\title{
O estudo das ondas sonoras por meio de uma atividade didática envolvendo leitura de um texto de divulgação científica ${ }^{+*}$
}

Daniele Correial

Doutoranda em Educação em Ciências

Maíra Angélica Bolfe ${ }^{2}$

Graduada em Física

Inés Prieto Schmidt Sauerwein ${ }^{3}$

Departamento de Física

Universidade Federal de Santa Maria

Santa Maria - RS

\section{Resumo}

Neste trabalho, apresentam-se e discutem-se os resultados de uma atividade didática que fez uso de estratégias de leitura para trabalhar um texto de divulgação científica. A atividade foi implementada em uma turma da $2^{a}$ série do Ensino Médio de uma escola pública. O objetivo foi promover a discussão dos conceitos físicos relacionados ao estudo de ondas sonoras a partir da música - assunto que faz parte da vida dos jovens - com o auxílio de um texto de divulgação científica que aborda uso, escolha e funcionamento dos diferentes tipos de fones de ouvido. Nesse sentido, a atividade didática contemplou aspectos científicos e tecnológicos, vinculando-os à saúde auditiva. Os resultados obtidos atingiram os objetivos propostos, pois a vinculação entre o conteúdo da área da Física e as informações do texto contribuiu para o entendimento do assunto e também despertou o interesse dos alunos pelas atividades de leitura. Percebeu-se que o tema tratado no texto e a forma como foram propostas as atividades de leitura potencializaram a abordagem do conhecimento científico en-

\footnotetext{
${ }^{+}$Study of sound waves in an educational activity using a popular science text

* Recebido: agosto de 2015.

Aceito: fevereiro de 2016.

${ }^{1}$ E-mail: daninhacorreia@gmail.com

2 E-mail: mairabolfe@gmail.com

${ }^{3}$ E-mail: ines.ufsm@gmail.com
} 
volvido no entendimento do uso e da escolha criteriosa dos distintos modelos de fones de ouvido. Conclui-se, assim, que o uso de textos de divulgação científica em aulas de Física pode ser um recurso de grande potencial didático para aquelas aulas que tenham como propósito desenvolver as habilidades de leitura e escrita articuladas aos conteúdos científicos a partir de temas presentes no cotidiano dos alunos.

Palavras-chave: Textos de divulgação científica; Leitura; Som; Física.

\begin{abstract}
This paper presents and discusses results of a didactic activity that uses reading strategies to study a popular science text. The activity was implemented in a 2nd year class of a public high school. The aim was to promote a discussion on physics concepts of sound waves by using music - a subject that is part of the young people's lives. The popular science text addresses use, choice and functionality of different types of headphones. In this sense, the didactic activity included scientific and technological aspects linking them to the hearing health. The results achieved the objectives, in which the link between the content and text information contributed on the understanding of the subject and it also stimulated the students for reading activities. In addition, it was noticed that the subject covered in the text and the way as the reading activities were proposed helped students to understand the scientific knowledge involved in the use and the careful choice of different models of headphones. To conclude, the use of popular science text in physics classes can be a great educational resource for classes that have the purpose to develop reading and writing skills articulated to the scientific content from themes existing in the routine of students.
\end{abstract}

Keywords: Popular science texts; Reading; Sound; Physics.

\title{
I. Introdução
}

A disciplina de Física da $2^{\mathrm{a}}$ série do Ensino Médio apresenta um extenso elenco de conteúdos programáticos, que, em linhas gerais, são desenvolvidos a partir das unidades de Hidrostática, Termodinâmica e Ondulatória. Entretanto, na maioria das vezes, o estudo de ondas sonoras não é abordado adequadamente ou é o último assunto previsto no cronograma letivo. Nesta segunda situação, o cenário é desfavorável, pois poucas aulas são destinadas a esse 
tema, sendo geralmente abordado por meio de aulas expositivas, as quais se restringem a definições de conceitos físicos e à formalização matemática.

Essa abordagem fragmentada e descontextualizada pode dificultar que o aluno perceba a presença das ondas sonoras nas situações vivenciadas em seu dia a dia, como o som emitido em um show de rock ou em seu fone de ouvido. Nesse contexto, uma das possíveis maneiras de estabelecer conexões entre a física envolvida no estudo do som e seus aspectos presentes no cotidiano é propor atividades de ensino que envolvam o uso de Textos de Divulgação Científica (TDC). O foco deste artigo é a análise de uma atividade de ensino que prevê essa articulação.

O som é um tema naturalmente fascinante e merecedor de um estudo detalhado em sala de aula. Para um ser humano ouvir um som, é preciso que este seja produzido e propagado até atingir o aparelho auditivo. Após, as características do som - frequência, amplitude, timbre, localização da fonte sonora, etc. - devem estimular o nervo auditivo, e este, por sua vez, deve conduzir tais informações, via células auditivas, para que o encéfalo interprete o som (RUI, STEFFANI, 2007). No campo da Física, o estudo da produção, propagação e percepção do som introduz uma gama enorme de conceitos físicos: vibração, frequência, período, velocidade de propagação, comprimento de onda, intensidade, timbre, ressonância, direção de propagação etc.

Os sons são classificados em agudos e graves. Os sons graves, popularmente chamados de sons baixos, têm maior comprimento de onda (pequena frequência). Já os sons agudos, também chamados de sons altos, têm menor comprimento de onda (maior frequência). A capacidade do ser humano para captar o som depende da sua intensidade e frequência. Em geral, o ouvido humano consegue captar vibrações com frequências compreendidas entre $20 \mathrm{~Hz}$ (sons graves) e $20.000 \mathrm{~Hz}$ (sons agudos). A menor intensidade sonora audível ou o limiar de audibilidade é de $10^{-12} \mathrm{~W} / \mathrm{m}^{2}$ (equivalente a $0 \mathrm{~dB}$ ). Quando o valor da intensidade for próximo a 120 $\mathrm{dB}$, sensações dolorosas podem ser causadas e lesões no aparelho auditivo podem surgir em caso de exposição prolongada a sons intensos.

No Brasil, existem limites legais para a exposição a sons contínuos, estabelecidos pela Portaria n. ${ }^{\circ}$ 3.214, de 8 de junho de 1978, do Ministério do Trabalho. Essa portaria define que uma pessoa pode permanecer em segurança em um ambiente com nível sonoro de $85 \mathrm{~dB}$ durante oito horas por dia. Com relação aos fones de ouvido intra-auriculares, é preciso ter um cuidado redobrado, pois estes têm maior potencial de desencadear problemas na audição por serem de inserção e aumentarem em até três vezes o nível do som emitido no canal do ouvido. Assim, é recomendado fazer intervalos a cada duas horas de uso, independentemente do modelo de fone de ouvido utilizado.

Tendo em vista a relevância e riqueza conceitual do tema som envolvido no funcionamento e conscientização do uso dos fones de ouvido, apresenta-se, neste manuscrito, uma Atividade Didática (AD) com o TDC "Para ouvir melhor"4 como uma maneira de abordar os conteúdos físicos a partir de um artefato que está presente no cotidiano dos alunos - o fone de ouvido. Assim, além de promover a vinculação do estudo das ondas sonoras ao uso desse

\footnotetext{
${ }^{4}$ Texto extraído da revista Veja, páginas 96 a 98, edição 2359, publicado em fevereiro de 2014.
} 
dispositivo, pretende-se trabalhar a leitura, a interpretação e a escrita nas aulas de Física. Nesse sentido, o presente artigo propõe-se a investigar quais eram os conhecimentos iniciais dos alunos sobre o uso de fones de ouvido antes de lerem o TDC, bem como averiguar quais relações os alunos estabeleceram entre as informações do TDC e o assunto ondas sonoras após a leitura e discussão do TDC.

É importante salientar que o hábito da leitura e da escrita deve ser cultivado também nas aulas de Física. Para tanto, é imprescindível que o docente da disciplina se considere um professor de leitura e, portanto, um formador de leitores. De acordo com Steffani e Damasio (2008),

O papel principal do professor de Física é ensinar o aluno a ler, a escrever e a expressar-se com propriedade sobre temas gerais e científicos, identificando o significado técnico-científico de termos que aparecem no seu dia a dia [...](STEFFANI, DAMASIO, 2008, p.145).

Sob essa perspectiva, nas aulas de Física, deve-se propiciar a leitura crítica de materiais de divulgação científica provenientes de diferentes meios de comunicação. O incentivo à leitura desses materiais potencializa a apropriação do conhecimento científico e propicia o desenvolvimento das competências de leitura e interpretação, contribuindo para a formação de cidadãos aptos a analisarem informações veiculadas nesses meios - hábitos e atitudes que devem permanecer após sua formação escolar.

Nesse sentido, os Parâmetros Curriculares Nacionais para o Ensino Médio (PCNEM) explicitam que:

Lidar com o arsenal de informações atualmente disponiveis depende de habilidades para obter, sistematizar, produzir e mesmo difundir informações [...]. Isso inclui ser um leitor crítico e atento das notícias científicas divulgadas de diferentes formas: vídeos, programas de televisão, sites da Internet ou notícias de jornais (BRASIL, 1999, p. 27).

Além disso, percebe-se que há uma ampla gama de materiais de divulgação científica disponíveis na internet, os quais são de fácil acesso ao professor. Nesse contexto, o número de publicações de propostas didáticas implementadas em sala de aula que envolvam o uso de TDC em aulas de Física vem crescendo nas últimas edições do Simpósio Nacional de Ensino de Física (SNEF). Em um mapeamento nas duas últimas atas do SNEF, constatou-se que no evento de 2013 foram publicados três trabalhos sobre o uso desse recurso em aulas de Física: um deles referente a sugestões de estratégias de leitura que podem ser utilizadas em aulas que envolvam o uso de TDC (RAMOS; PIASSI, 2013); e os outros dois trabalhos, um sobre nanotecnologia (OLIVEIRA; ALMEIDA; FERREIRA, 2013) e o outro sobre dinâmica de Newton (PASCOALOTO; LONDERO; BRUNO JUNIOR, 2013), apresentavam propostas didáticas implementadas em sala de aula. Já no XXI SNEF, ocorrido em 2015, foram publicados seis trabalhos sobre a temática - um referente à proposta didática não implementada sobre 
termodinâmica (ASSIS; DICKMAN, 2015), e os outros cinco relacionados a propostas didáticas implementadas em sala de aula acerca dos seguintes temas: dilatação anômala (BOLFE; CORREIA; SAUERWEIN, 2015), energia mecânica (SETLIK; HIGA, 2015), viscosidade (DECIAN; CORREIA; SAUERWEIN, 2015), propriedades da luz (SILVA et al., 2015) e física contemporânea (SILVA; ZANOTELLO, 2015).

Por outro lado, nos dois últimos eventos do SNEF, evidenciou-se a carência de trabalhos envolvendo o uso de TDC para abordar o conteúdo de ondas sonoras. Diante disso, este estudo tem o propósito de apresentar os resultados de uma AD destinada a abordar de maneira contextualizada o assunto de ondas sonoras por meio de um TDC. A proposta didática foi implementada em uma turma da $2^{\text {a }}$ série do Ensino Médio de uma escola pública do município de Santa Maria, Rio Grande do Sul, no mês de novembro de 2014.

O presente artigo está organizado em quatro partes. Além desta introdutória, apresentase o referencial teórico sobre o uso de TDC em aulas de Física; após, são expostos os procedimentos metodológicos; em seguida, discutem-se os resultados obtidos com a implementação da atividade; e, por último, discorre-se sobre as considerações finais deste estudo e suas implicações para o ensino de Física.

\section{Por que utilizar TDC no ensino de Física?}

Atualmente, faz-se necessário, nas aulas de Física, vincular a abordagem dos conteúdos científicos a temas atuais relacionados à ciência, à tecnologia e/ou a aplicações no cotidiano. Uma das maneiras de propiciar tal articulação é por meio dos materiais de divulgação científica, que, segundo Salém e Kawamura (1996), podem ser encontrados de diversas formas - em publicações escritas (jornais e revistas), nos meios de comunicação eletrônica e em mídias audiovisuais. Esses materiais têm como função principal divulgar a ciência à população, trazendo informações, ideias e conceitos da ciência de forma mais clara.

Desse modo, um dos materiais de divulgação científica que podem ser utilizados em sala de aula é o TDC. Este contempla a discussão de temas sobre "ciência e tecnologia" e "acontecimentos do cotidiano" em linguagem acessível e destinada a um público não especializado (SALÉM; KAWAMURA, 1996; TERRAZZAN; GABANA, 2003; MENEGAT; CLEMENT; TERRAZZAN, 2007; FERREIRA; QUEIROZ, 2012; ROCHA; 2012a; ZANOTELLO; ALMEIDA, 2013). Contudo, Terrazzan e Gabana (2003) mencionam que os TDC normalmente não aprofundam detalhes específicos nem usam simbologia matemática como costuma acontecer nos Livros Didáticos (LD), pois têm uma função didática diferente daquela prevista para os LD. Ademais, os TDC geralmente apresentam os conhecimentos científicos a partir do tratamento de suas aplicações ou por meio de explicações sobre o estudo de fenômenos presentes no cotidiano das pessoas.

A esse respeito, Martins, Cassab e Rocha (2001) sinalizam que o uso do TDC pode gerar muitos benefícios, como, por exemplo, acesso a uma maior diversidade de informações, desenvolvimento de habilidades de leitura, domínio de conceitos, capacidade de argumentação 
e aprendizado de elementos da terminologia científica. Além disso, segundo Almeida (1993), os TDC podem ser utilizados como meio para gerar nos alunos atitudes, curiosidade científica e consciência crítica. Nessa direção, Menegat (2007) salienta que o desenvolvimento dessas habilidades faz com que o aluno estabeleça novos significados para os assuntos tratados em sala de aula.

Entretanto, Rocha (2012b) explicita que a utilização de materiais de divulgação científica deve ser acompanhada de uma reflexão e análise cuidadosa por parte dos professores acerca do conteúdo que será transposto. Dessa forma, é preciso que se faça um estudo detalhado das informações do TDC para que, assim, a AD planejada alcance os objetivos previamente estabelecidos.

Apesar das potencialidades do TDC no que se refere tanto ao favorecimento da apropriação de conhecimentos científicos quanto ao desenvolvimento de habilidades de leitura e escrita, percebe-se que existem poucas publicações em nível nacional relacionadas ao uso de TDC em aulas de Física no Ensino Médio. Em um levantamento realizado nos principais periódicos nacionais ${ }^{5}$, foram encontrados onze artigos referentes a relatos de implementações em sala de aula envolvendo o uso de TDC. Desta amostra, selecionaram-se neste estudo artigos que apresentaram em seus títulos e/ou resumos os seguintes termos: "texto", "divulgação científica", "ensino médio", "Física" e "leitura".

A partir da análise desses onze artigos selecionados, constatou-se que os TDC são utilizados para abordar os seguintes assuntos: ressonância magnética nuclear (ASSIS et al., 2012; SILVA; ALMEIDA, 2014; SILVA; ALMEIDA, 2015); força de atrito (ALMEIDA; SILVA; BARBICHAK, 1999); massa, peso, gravitação universal e velocidade de escape (ASSIS, TEIXEIRA, 2007); gravitação universal (DIAS; SANTOS; SOUZA, 2004); luz e outras formas de radiação eletromagnética (ALMEIDA; MOZENA, 2000); vida extraterrestre, quedas de corpos e lançamento de projéteis (ALMEIDA; SILVA; MACHADO, 2001); natureza da luz e sua utilidade (SILVA; KAWAMURA, 2001); movimento, leis de Newton e esportes (SETLIK; HIGA, 2014); física quântica e sua relevância tecnológica (SILVA; ALMEIDA; 2015); e som (BORGES; RODRIGUES, 2005).

Com relação às estratégias de leitura empregadas nas atividades com TDC, percebeuse que os autores dos artigos referentes aos temas de ressonância magnética nuclear (SILVA; ALMEIDA, 2014; SILVA; ALMEIDA, 2015), física quântica e suas relevâncias (SILVA; ALMEIDA, 2015) e força de atrito e gravitação universal (ALMEIDA; SILVA; BARBICHAK,

\footnotetext{
${ }^{5}$ Revistas analisadas até o primeiro volume publicado em 2015: Ciência \& Educação (2003-2015), Revista Brasileira de Ensino de Física (1999-2015), Caderno Brasileiro de Ensino de Física (1999-2015), Revista Brasileira de Educação (2000-2015), Revista Brasileira de Pesquisa em Educação em Ciências (2001-2015), Ensaio: Pesquisa em Educação em Ciências (2004-2015), Alexandria: Revista de Educação em Ciência e Tecnologia (20082015), Experiência em Ensino de Ciência (2006-2015), Investigações em Ensino de Ciências (1999-2015) e Ciência \& Ensino (1999 - 2015).
} 
1999; DIAS; SANTOS; SOUZA, 2004) realizaram atividades de durante a leitura que envolveram questões sobre o texto e, após, concederam explicações sobre o assunto. Como atividade de pós-leitura, foram entregues para os alunos questões para averiguar o seu entendimento sobre o TDC.

No artigo referente ao assunto som (BORGES; RODRIGUES, 2005), os alunos resolveram um problema como atividade de pré-leitura e responderam algumas questões durante a leitura. É importante salientar que, neste trabalho, também foram desenvolvidas outros exercícios (antes e após a leitura), que englobaram questionários e atividades experimentais sobre a física do som.

Os autores Almeida, Silva e Machado (2001), por sua vez, apresentam atividades de leitura diferentes para trabalhar os temas vida extraterrestre, queda de corpos e lançamento de projéteis. Assim, esses autores relatam a realização da etapa de durante a leitura, em que são propostas questões sobre o tema vida extraterrestre para os alunos responderem. Já para os assuntos queda de corpos e lançamento de projéteis, identificou-se a realização de atividades de pré-leitura, que envolveram questões sobre essas temáticas a serem respondidas pelos alunos. Durante a leitura, os alunos formularam questões sobre o texto. Assis e seus colaboradores (2012), que também tratam do assunto ressonância nuclear magnética, relatam que foi realizada uma leitura silenciosa do texto e que, em seguida, como atividade de pós-leitura, houve a discussão do assunto.

Outros dois artigos analisados utilizaram o TDC associado a outros recursos didáticos em um conjunto de aulas. No caso do artigo sobre o tema natureza da luz, por exemplo, da autoria de Silva e Kawamura (2001), há relato sobre aulas expositivas, atividades experimentais, leituras de textos do LD e leituras de TDC. Neste trabalho, os autores descrevem que foram realizadas atividades de pré-leitura com os TDC (em que forma propostas questões iniciais relacionadas ao tema natureza da luz e aos assuntos dos TDC) e pós-leitura (em que os alunos organizaram um seminário sobre os TDC disponibilizados pelo professor e também sobre as demais atividades desenvolvidas nas aulas). Por fim, os alunos responderam um questionário avaliando todas as atividades desenvolvidas.

Já Almeida e Mozena (2000), autoras do artigo referente ao assunto luz e outras formas de radiação, relatam um conjunto de treze encontros que englobou questionários, atividades experimentais, filmes, aulas expositivas e uso de um TDC. Neste artigo em específico, o trabalho com o TDC envolveu atividades durante a leitura, com questões a serem respondidas pelos alunos, e discussão do TDC mediada pelo professor. Após o término das treze aulas, foi aplicado um questionário final sobre os tópicos discutidos durante as aulas.

No artigo de Setlik e Higa (2014), que se refere ao tema movimento e leis de Newton, a atividade com TDC envolveu todos os alunos em uma leitura coletiva. Após a leitura, os alunos foram orientados a relacionar as informações do texto e o conteúdo estudado previamente com uma modalidade esportiva. Já Assis e Teixeira (2007), autoras do artigo que trata 
dos temas massa, peso, campo gravitacional e velocidade de escape, propuseram leitura em voz alta do texto e um questionário como atividade de pós-leitura.

Em síntese, os onze artigos analisados não apresentam AD implementadas em sala de aula envolvendo TDC para abordar o conteúdo de ondas sonoras nas aulas de Física. Além disso, não se percebe explicitamente a preocupação em trabalhar a leitura e a escrita nas aulas de Física mediante proposição, em uma mesma atividade, de tarefas para antes, durante e após a leitura a partir do uso do TDC.

Diante disso, o presente artigo apresenta os resultados de uma AD implementada em sala de aula com TDC. Tal atividade viabilizou a discussão do assunto ondas sonoras, bem como promoveu a leitura e discussão do TDC que apresenta informações acerca do uso e da escolha de diferentes modelos de fones de ouvido. Levando em consideração que este dispositivo está presente no dia a dia dos jovens, torna-se imprescindível promover nas aulas de Física a conscientização sobre o uso indevido e excessivo dos fones de ouvido e suas implicações na saúde auditiva, assim como a discussão e explicação do modo como a Física está envolvida no funcionamento deste aparelho.

\section{Procedimentos metodológicos}

Este trabalho foi desenvolvido durante o estágio de pré-regência e regência em Física na Universidade Federal de Santa Maria (UFSM). No período de pré-regência, uma das autoras deste artigo planejou um conjunto de aulas que foram executadas no segundo semestre de 2014 e que contava com duas aulas que envolveram o uso de TDC. Para tanto, as professoras responsáveis (e autoras deste artigo) pela disciplina de Estágio Supervisionado em Ensino de Física ofereceram as estagiárias uma oficina de leitura e escrita que subsidiou o planejamento das aulas com TDC. Após o término da oficina, realizou-se o planejamento das aulas com TDC pelas estagiárias. Concluída esta etapa, procedeu-se à apresentação das AD com TDC, primeiramente, por meio de aulas simuladas e, posteriormente, por meio da execução em sala de aula de cada $\mathrm{AD}$ no período de regência.

A abordagem de pesquisa, a partir desta implementação, é de natureza qualitativa. Os instrumentos de coleta de dados (registros escritos dos alunos e de observação da estagiária) foram obtidos dentro do contexto natural, a sala de aula. Segundo Bogdan e Biklen (1994, p. 47), "na investigação qualitativa a fonte direta de dados é o ambiente natural, constituindo o investigador o instrumento principal”.

A turma da estagiária contou com a participação de 17 alunos da $2^{\mathrm{a}}$ série do Ensino Médio de uma escola pública estadual do município de Santa Maria, Rio Grande do Sul. A coleta de dados desta AD com o TDC "Para ouvir melhor" ocorreu por meio do diário de aula e do material entregue pelos alunos (respostas dadas às questões propostas e diagramas). A AD teve o intuito de promover a leitura, discussão e contextualização de conceitos relacionados ao estudo de ondas sonoras por meio do uso do TDC, incluindo, por exemplo, a propagação, a 
direção e o sentido da onda sonora, assim como as características fisiológicas do som: intensidade, timbre e altura. Dessa forma, discutiu-se a conceituação física necessária ao entendimento das informações presentes no TDC (por exemplo: como funcionam e quais as diferenças apresentadas nos diferentes modelos de fones de ouvido), bem como os aspectos relacionados ao uso, à escolha, às vantagens e às desvantagens dos diferentes modelos de fone de ouvido.

Para que fosse possível discutir os conteúdos físicos, em uma aula anterior ao início da implementação da AD com TDC (ilustrada na Tabela 1), foi ministrada uma exposição sobre as características fisiológicas do som. A AD foi organizada em três etapas nas quais se realizaram atividades antes, durante e após a leitura do TDC (SOLÉ, 1998).

Tabela 1 - Síntese das atividades desenvolvidas na AD.

\begin{tabular}{|c|c|c|c|}
\hline $\begin{array}{c}\text { Data da im- } \\
\text { plementação } \\
\text { da } \mathrm{AD}\end{array}$ & $\begin{array}{l}\text { Etapa da ati- } \\
\text { vidade de lei- } \\
\text { tura }\end{array}$ & Atividades desenvolvidas & Objetivos \\
\hline 27/11/2014 & $\begin{array}{l}(1 \mathrm{~A}) \text { - Antes } \\
\text { da leitura (du- } \\
\text { ração de } 20 \\
\text { minutos) }\end{array}$ & $\begin{array}{l}\text { 1. Os alunos responderam às } \\
\text { seguintes questões: } \\
\text { Q1) Você usa fones de ouvido? Com } \\
\text { que frequência? } \\
\text { Q2) O que você leva em considera- } \\
\text { ção ao comprar um fone de ouvido? } \\
\text { Q3) Você acha que o uso de fones de } \\
\text { ouvido é prejudicial à saúde audi- } \\
\text { tiva? Justifique. }\end{array}$ & $\begin{array}{l}\text { - Averiguar os } \\
\text { conhecimentos dos alunos } \\
\text { acerca do uso de fones de } \\
\text { ouvido antes de fazer a } \\
\text { leitura do texto. }\end{array}$ \\
\hline $\begin{array}{l}27 / 11 / 2014 \\
\text { (entrega das } \\
\text { questões e do } \\
\text { TDC para os } \\
\text { alunos) }\end{array}$ & $\begin{array}{l}\text { (2B) - Durante } \\
\text { a leitura } \\
\text { (tarefa reali- } \\
\text { zada em casa) }\end{array}$ & $\begin{array}{l}\text { 2. Os alunos responderam às } \\
\text { seguintes questões: } \\
\text { Q1) Explique como a onda sonora } \\
\text { chega até nossos ouvidos? } \\
\text { Q2) Qual é a natureza e qual é a dire- } \\
\text { ção de propagação das ondas sono- } \\
\text { ras? } \\
\text { Q3) Dos fones de ouvido descritos } \\
\text { no texto, qual você compraria? Justi- } \\
\text { fique. } \\
\text { 3. Os alunos foram orientados a ler e } \\
\text { anotar as dúvidas que surgissem } \\
\text { durante a leitura do TDC; }\end{array}$ & $\begin{array}{l}\text { - Verificar o conhe- } \\
\text { cimento dos alunos com } \\
\text { relação ao conteúdo de } \\
\text { ondas sonoras estudado } \\
\text { em aulas anteriores; } \\
\text { - Analisar quais critérios } \\
\text { foram uti-lizados na } \\
\text { escolha do fone de ouvido } \\
\text { e suas possíveis rela-ções } \\
\text { com as infor-mações lidas } \\
\text { no TDC. }\end{array}$ \\
\hline 28/11/2014 & $\begin{array}{l}\text { (3C) - Após a } \\
\text { leitura } \\
\left(\begin{array}{r}1 \text { hora- } \\
\text { aula })\end{array}\right.\end{array}$ & $\begin{array}{l}\text { 4. Discussão do TDC (questões } \\
\text { realizadas na etapa 2B e trechos pré- } \\
\text { selecionados). } \\
\text { 5. Os grupos de alunos foram } \\
\text { orientados a elaborar um diagrama } \\
\text { relacionando as informações do TDC } \\
\text { ao conteúdo de ondas sono-ras } \\
\text { estudado. }\end{array}$ & $\begin{array}{l}\text { 1- Discutir o TDC e sua } \\
\text { relação com o conteúdo de } \\
\text { ondas sonoras e as ques- } \\
\text { tões propostas nas etapas } \\
\text { anteriores. }\end{array}$ \\
\hline
\end{tabular}

Fonte: Os autores. 
Conforme descrito na Tabela 1, a AD foi implementada em dias diferentes - 27/11/14 e 28/11/14. No primeiro dia, foram estudadas as características fisiológicas do som, e, em seguida, iniciou-se a primeira etapa ( $1 \mathrm{~A}$ - antes da leitura) da $\mathrm{AD}$, em que os alunos responderam e entregaram as questões iniciais que tinham o objetivo de analisar os conhecimentos prévios sobre o uso e a escolha de fones de ouvido. Após, procedeu-se a uma breve discussão com os alunos sobre as respostas dadas a essas questões. Logo, com a etapa 1A finalizada, passou-se para a segunda etapa ( $2 \mathrm{~B}$ - durante a leitura), em que as atividades propostas tinham como objetivos: (i) verificar os conhecimentos dos alunos acerca do assunto de ondas sonoras (estudado em aulas anteriores); e (ii) analisar quais critérios os alunos utilizariam para escolher os fones de ouvido após a leitura no texto. Assim, para iniciar esta etapa, foram entregues aos alunos o TDC para ser lido e três questões para serem respondidas como tarefa de casa.

Desse modo, no início da segunda aula, os alunos entregaram as questões propostas na etapa 2B. Com esse material em mãos, a professora iniciou a terceira etapa (3C - após a leitura), cujos objetivos foram discutir o TDC; sanar as dúvidas em relação às questões respondidas nas etapas 1A e 2B; e sintetizar, em um diagrama, as informações do TDC, relacionando-as ao conteúdo de ondas sonoras (tarefa realizada pelos alunos em grupo). A discussão das questões esteve sempre vinculada às interpretações do TDC e, portanto, apoiada na localização de trechos que auxiliaram a compreender os conteúdos conceituais. Nesse sentido, a presente etapa teve como intuito relacionar o conteúdo de ondas sonoras com as informações do TDC, bem como destacar aspectos relacionados ao uso e às particularidades de cada modelo de fone de ouvido abordado no TDC. A seguir, são ilustrados alguns exemplos de trechos do TDC que foram discutidos:

TRECHO 1: Especialistas alertam, porém, para o seu uso abusivo, que podem causar danos irreversíveis à audição. "Quanto mais alto o volume e mais prolongado o tempo de uso, maior será o risco de uma lesão auditiva”, [...] (p. 96).

TRECHO 2: HEADPHONE: Cada vez mais popular, o headphone envolve a orelha e é o modelo mais recomendado [...] Ideal para: uso em locais barulhentos [...] Desvantagens: por causa do tamanho do apetrecho [...] (p. 97).

TRECHO 3: IN-EAR: O modelo intra-auricular entra no canal do ouvido e isola boa parte do som externo [...] Ideal para: esportistas, pois é um dos modelos mais confortáveis [...] Desvantagens: Para evitar problemas auditivos, é preciso usar em volume baixo [...] (p. 97)

TRECHO 4: EARPAD: Também chamado de supra-auricular [...] Ideal para: uso prolongado. [...] Desvantagens: Não possui bom isolamento [...] (p. 97).

TRECHO 5: EARBUD: É pequeno e fica preso [...] Ideal para: ambientes silenciosos. [...] Desvantagens: o earbud possui baixo isolamento [...] (p. 97). 
TRECHO 6: Sensibilidade: é o volume máximo que o fone pode alcançar, em decibéis (dB). O ideal é que seja maior que $100 \mathrm{~dB}$. Mas atenção: não é porque a sensibilidade do fone é maior que você deve sair ouvindo música mais alto - a não ser que queira ficar surdo ainda na juventude. Use esse número isto sim, como referência da fidelidade sonora de que o aparelho é capaz alcançar (p. 97).

TRECHO 7: Surdez entre os Jovens: Tópicos - controle de volume; Faça intervalos; Fique atento a sintomas (p. 101).

Com isso, alertou-se que o uso indevido e excessivo de fones de ouvido pode causar problemas auditivos (trechos 1 e 7) e destacaram-se as vantagens e desvantagens dos diferentes modelos de fones de ouvido (trechos 2, 3, 4,5). Fez-se, também, a articulações dos conteúdos físicos (ruído, intensidade e altura do som) com as informações do TDC (trechos 1, 6 e 7).

Juntamente com os trechos supracitados, especialmente o trecho 6, chamou-se a atenção dos alunos quanto ao tempo de exposição a determinadas intensidades sonoras. Para ilustrar o período máximo a que uma pessoa pode ficar exposta a determinada fonte sonora (sem causar danos à saúde auditiva), utilizaram-se informações de outro texto ${ }^{6}$. Cabe salientar que o TDC não apresentava tais informações, motivo pelo qual se julgou necessário proceder a tal complementação.

A análise detalhada dos dados obtidos a partir da implementação da AD é apresentada na seção seguinte.

\section{Análise e discussão dos resultados}

Primeiramente, será discutida a análise das respostas dadas pelos alunos às questões Q1, Q2 e Q3 referentes à primeira etapa, ou seja, ao momento anterior à leitura (1A). A etapa 1A tinha o objetivo de investigar aspectos relacionados ao uso e à escolha dos fones de ouvido pelos alunos.

Analisando a questão Q1 (dividida em duas partes, conforme Tabelas 2 e 3), pode-se perceber que a maioria dos estudantes utiliza fones de ouvido diariamente (ver Tabelas 2 e 3 ).

Tabela 2 - Respostas dadas à questão Q1, parte 1 (1A).

\begin{tabular}{l|l}
\hline \multicolumn{2}{c}{ Questão 1: Parte 1: Você usa fones de ouvido? } \\
\hline \multicolumn{1}{c}{ Exemplo de resposta } & \multicolumn{1}{c}{ Número de alunos } \\
\hline Sim & 15 \\
\hline Não & 1 \\
\hline Às vezes & 1 \\
\hline
\end{tabular}

Fonte: Os autores.

\footnotetext{
${ }^{6}$ Música alta demais no fone de ouvido pode prejudicar audição: veja cuidados. Fonte: <http://tecnologia.uol. com.br/noticias/redacao/2014/01/17/musica-alta-demais-no-fone-de-ouvido-pode-prejudicar-audicao-veja-cuidados.htm>.
} 
Tabela 3 - Respostas dadas à questão Q1, parte 2 (1A).

\begin{tabular}{l|l}
\hline \multicolumn{2}{c}{ Questão 1: Parte 2: Com que frequência? } \\
\hline \multicolumn{1}{c}{ Exemplo de resposta } & \multicolumn{1}{c}{ Número de alunos } \\
\hline Quase todo dia & 2 \\
\hline Todo dia & 11 \\
\hline Às vezes & 2 \\
\hline Não respondeu & 2 \\
\hline
\end{tabular}

Fonte: Os autores.

Analisando a Tabela 3, percebe-se que a maioria dos alunos faz o uso do fone de ouvido. Sendo assim, é importante discutir em sala de aula assuntos que façam parte do cotidiano do aluno, como é o caso do fone de ouvido.

A discussão de temas que estão presentes nas atividades diárias dos alunos, sem dúvida, pode potencializar a abordagem dos conteúdos disciplinares como as ondas sonoras, foco deste estudo. Nesse sentido, Rocha (2012a) aponta que o TDC tem o potencial de estabelecer e vincular os conteúdos disciplinares ao cotidiano do aluno:

O texto de divulgação científica torna-se um material interessante, rico e sintonizado com o cotidiano quando passa a constituir a "ponte” entre os conteúdos curriculares e o mundo do aluno, fazendo conexão entre o que se aprende na escola e o que está fora dela (ROCHA, p. 135, 2012a).

A segunda questão, Q2, da etapa 1A, tinha o intento de investigar o que os alunos levam em consideração na hora de comprar um fone de ouvido. Percebe-se que os discentes elencaram mais de um critério para essa escolha, os quais estão dispostos na Tabela 4.

Tabela 4 - Respostas dadas à questão Q2 (1A).

Questão 2: O que você leva em consideração ao comprar um fone de ouvido?

\begin{tabular}{c|c}
\hline Exemplo de resposta & Número de alunos \\
\hline Isolamento & 2 \\
\hline Qualidade do som & 9 \\
\hline Modelo & 4 \\
\hline Potência & 4 \\
\hline Preço & 3 \\
\hline Marca & 1 \\
\hline Não respondeu & 5 \\
\hline
\end{tabular}

Fonte: Os autores. 
Nessa questão, alguns alunos elencaram mais de um critério de escolha, razão pela qual as respostas foram computadas em mais de uma categoria. Assim, com base na Tabela 4, evidencia-se que a maioria dos alunos citou a qualidade do som (definida pelos alunos como sendo um "som nítido e sem ruído") como sendo o principal atributo levado em consideração ao adquirir um fone de ouvido. Durante a discussão dessa questão, os alunos citaram, além da qualidade do som, o preço e o design do aparelho como aspectos importantes.

No entanto, é importante destacar que a qualidade do som do fone de ouvido está relacionada à potência de entrada e à impedância, de modo que, quanto maior for a potência de entrada do fone de ouvido, melhor será a qualidade do som. Além disso, é preciso verificar a potência de saída do aparelho de som a que o fone será acoplado, pois esta deve ser sempre inferior à potência de entrada. Outro fator importante para que o som tenha uma boa qualidade é a impedância do fone, que deve ser compatível com a do aparelho de som, pois, para um fone de ouvido ter um som de boa qualidade e sem distorção, é necessário que o produto tenha um ajuste correto da potência de entrada e da impedância.

A terceira questão, Q3, da etapa 1A, tinha o intuito de investigar o conhecimento dos alunos sobre o uso dos fones de ouvido. As respostas dadas a essa questão estão na Tabela 5, exposta a seguir.

Tabela 5 - Respostas dadas à questão Q3 (1A).

Questão 3: Você acha que o uso de fones de ouvido é prejudicial à saúde auditiva? Justifique.

\begin{tabular}{l|c|c}
\hline Exemplo de resposta & Número de alunos & Justificativas (total de alunos) \\
\hline Sim & 16 & $\begin{array}{l}\text { Por causa do volume alto (15) } \\
\text { Pode machucar o ouvido (1) }\end{array}$ \\
\hline Não & 1 & Não justificou (1) \\
\hline
\end{tabular}

Fonte: Os autores.

Observando a Tabela 5, percebe-se que a maioria dos alunos menciona que utilizar o fone de ouvido no "volume alto" para ouvir música pode causar danos à saúde auditiva. Entretanto, os alunos parecem desconhecer que o tempo de exposição excessivo a determinadas intensidades sonoras também se caracteriza como um fator desencadeador de problemas relacionados à perda de audição. Logo, discutir esse assunto em sala de aula propicia não só a inserção da conceituação física necessária ao entendimento da relação entre "tempo de exposição" e "intensidade sonora", mas também a conscientização do aluno de que o uso indevido e excessivo dos fones pode causar problemas auditivos.

Já a questão Q1, da etapa 2B, tinha o objetivo de averiguar se os alunos, ao responderem esta questão, apresentariam uma explicação física baseada nos conteúdos trabalhados em aulas anteriores. Analisando as respostas, notou-se que os 17 alunos responderam às perguntas corretamente, como pode ser verificado nos trechos transcritos a seguir: 
A onda sonora que chega aos nossos ouvidos é uma sequência de perturbações transportadas pelo ar e que trazem energia até nossos tímpanos.

O som é uma onda mecânica que se comprime e descomprime as moléculas do meio. Logo, ele chega até nossos ouvidos por meio de vibrações. O fenômeno ondulatório propagase num único plano, apresenta uma intensidade, frequência e duração.

Por meio de vibrações, ou seja, uma sequência de perturbações transportadas no ar e que trazem energia até nosso tímpano.

Na confecção destas respostas, percebe-se que os alunos conseguiram apresentar uma explicação física baseada em conceitos envolvidos no estudo das ondas sonoras. Também é possível notar que as respostas dos alunos demonstram uma explicação bem detalhada do assunto, o que denota que estes procuraram consultaram outras fontes, como o LD, por exemplo.

Para a questão Q2, da etapa 2B, que tinha como objetivo avaliar se os alunos conseguiriam classificar a onda sonora em relação à natureza e à direção de propagação, percebeuse, ao analisar as respostas dadas, que $82 \%$ dos alunos classificaram corretamente a onda sonora quanto à natureza, que é mecânica. Já em relação à direção de propagação, $41 \%$ dos alunos identificaram que a onda estudada se propagava de forma longitudinal, respondendo corretamente à questão proposta.

Na questão Q3, da etapa 2B, o intento consistia em analisar quais aspectos seriam utilizados pelos alunos para escolher o fone de ouvido e quais suas possíveis relações com as informações do TDC. Na Tabela 6, estão descritas as respostas dos discentes.

Tabela 6 - Respostas dadas à questão Q3 (2B).

\begin{tabular}{c|c|c}
\hline \multicolumn{2}{c}{ Questão 3: Dos fones de ouvido descritos no texto, qual você compraria? Justifique. } \\
\hline Exemplo de resposta & Número de alunos & \multicolumn{1}{c}{ Justificativas (total de alunos) } \\
\hline Headphone & 8 & $\begin{array}{l}\text { Mais convencional (1) } \\
\text { Maior isolamento de ruídos (7) }\end{array}$ \\
\hline Earpad & 3 & $\begin{array}{l}\text { Confortável (2) } \\
\text { Ideal para uso prolongado (1) }\end{array}$ \\
\hline In-ear & 1 & Isola parte do som externo (1) \\
\hline Earbud & 5 & $\begin{array}{l}\text { Fácil de colocar (5) } \\
\text { Pequeno (2) } \\
\text { Preço acessível (2) } \\
\end{array}$ \\
& 5 & Simples (1) \\
\hline
\end{tabular}

Fonte: Os autores.

Nessa questão, alguns alunos mencionaram mais de um critério de escolha, sendo computados, por isso, em mais de uma categoria. Com base na análise das respostas apresentadas da Tabela 6, percebe-se que os alunos se basearam nas informações do TDC para escolher o 
fone de ouvido que atendesse a suas expectativas pessoais, tendo apresentado justificativas distintas para optar por um dos quatro modelos descritos no TDC. O fone de ouvido mais mencionado foi o Headphone pelo fato de ter um melhor isolamento acústico; outro fone que chamou a atenção dos estudantes foi o Earbud por ser pequeno e ter um preço acessível. Além disso, durante a discussão dessa questão, a maioria dos alunos relatou que, embora utilizasse diariamente o modelo In-ear, apreciava o Headphone devido ao seu melhor isolamento acústico. $\mathrm{Na}$ fala dos alunos: "O Headphone pode ser o melhor, mas devido ao preço (...), o jeito é comprar o In-ear que além de ser mais barato tem uma aparência melhor, embora seja incômodo por ser intra-auricular".

Após o término da etapa 2B, passou-se para a discussão do TDC, bem como à ênfase, em momentos oportunos, a alguns de seus trechos (destacados anteriormente). Neste caso percebeu-se que as informações abordadas no TDC despertaram a curiosidade dos alunos, principalmente no que se refere aos aspectos que diferenciavam os modelos de fones de ouvido.

Alguns discentes perguntaram qual seria a intensidade adequada para se usar o fone de ouvido sem causar danos ao aparelho auditivo. Neste momento, discutiu-se o trecho 6 do TDC, destacando aos alunos que não se deve utilizar o fone de ouvido no volume máximo, já que o uso indevido deste dispositivo pode causar lesão no aparelho auditivo. Comentou-se com os alunos, também, que as pessoas podem ficar expostas a determinada fonte sonora por certo tempo apenas, o que foi ilustrado por meio da discussão dos dados extraídos do texto de apoio "Música alta demais no fone de ouvido pode prejudicar audição: veja cuidados", referente à intensidade emitida por diferentes fontes sonoras e ao tempo máximo de exposição diária. Neste momento, percebeu-se que os alunos estavam bastante interessados, curiosos e participativos, principalmente após o relato de um dos alunos: "Tenho problema de audição no ouvido direito porque moro perto de um local onde ocorrem muitas construções".

Os alunos manifestaram, então, curiosidade em saber a intensidade de outras fontes sonoras, bem como o tempo de exposição permitido. Sendo assim, ao procurarem tais informações no LD, encontraram uma tabela que ilustrava alguns exemplos de intensidades emitidas por fontes sonoras distintas e seus respectivos tempos máximos de exposição. Em seguida, os alunos observaram, por exemplo, que uma intensidade sonora de $110 \mathrm{~dB}$ correspondia a um show de rock, à qual eles poderiam ficar expostos por um tempo máximo de 30 minutos se estivessem a dois metros de distância da caixa de som.

Neste caso, foi necessário procurar tais dados no LD para complementar as informações tanto do TDC quanto do texto de apoio utilizado. De acordo com Zanotello e Almeida (2013), o TDC é um material complementar às aulas, não substituindo, assim, o LD. Desse modo, a elaboração de uma atividade com TDC precisa ser planejada e requer que o professor complemente as informações por meio da utilização de outras fontes de consulta, como, por exemplo, o LD.

Observa-se, ainda, que a discussão mediada pelo TDC acerca do uso de fones de ouvido foi de extrema relevância, pois os alunos refletiram sobre seus hábitos e suas atitudes e 
perceberam a aplicabilidade do conteúdo de ondas sonoras em seu dia a dia. Portanto, esta AD possibilitou contextualizar o conhecimento científico e, assim, discutir aspectos relacionados ao uso, à escolha e ao funcionamento do fone de ouvido.

Concluída a etapa de discussão do TDC, solicitou-se aos alunos que formassem grupos de oito e que cada grupo elaborasse um diagrama baseado nas informações do TDC e no conteúdo de ondas sonoras estudado. Desses oito grupos, cinco elaboraram diagramas baseados nas informações presentes no TDC, como é o caso do exemplo mostrado na Fig. 1.

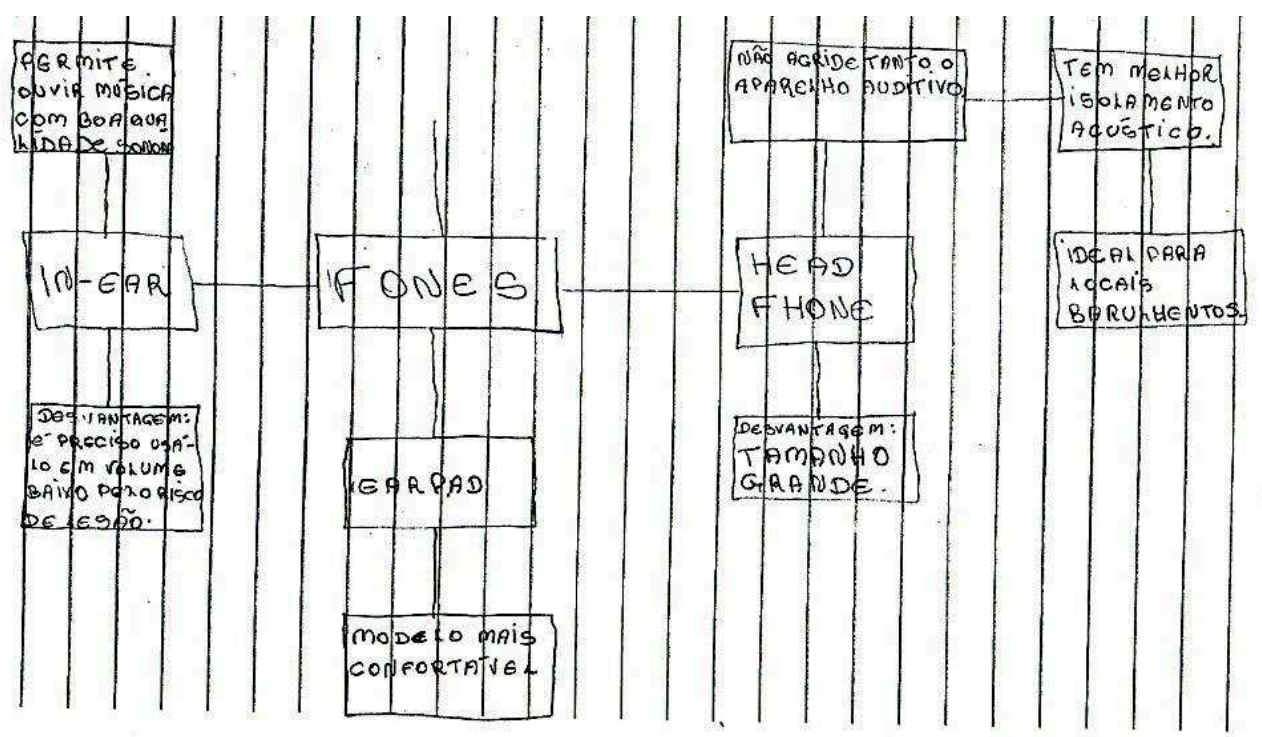

Fig. 1 - Diagrama do grupo 4. Fonte: Os autores.

Pode-se perceber, no diagrama elaborado pelo grupo 4 (representado na Fig. 1), que os alunos se restringiram a resumir algumas vantagens e desvantagens dos modelos de fones In-ear, Earpad e Headphone que estavam descritas no TDC. Dos cinco grupos que construíram diagramas apenas com as informações presentes no texto, percebe-se que quatro destes grupos citaram o Headphone, suas vantagens e desvantagens. Este modelo é classificado no texto como o menos prejudicial à saúde auditiva, informação que chamou bastante a atenção dos alunos. Entretanto, o fato de os estudantes se restringirem a sintetizar apenas as informações do texto pode, de um lado, estar relacionado à tentativa de atribuir ao diagrama certa fidelidade perante as informações do TDC. De outro, pode ser um indício de que nem todos os alunos perceberam a importância dos conhecimentos físicos relacionados ao uso dos fones de ouvido, uma vez que alguns grupos construíram seus esquemas sem mencionar tais conhecimentos, limitando-se a apresentar o que estava no TDC.

Entretanto, o diagrama produzido pelo grupo 3 (ilustrado na Fig. 2) demonstra que os alunos se posicionaram criticamente sobre as informações do fone Earpad presentes no texto, o que indica a interação entre os alunos e o TDC. Para Francisco Junior (2011), 
[...] A interação com o texto é um dos princípios básicos da leitura crítica. A leitura crítica é calcada pela suspeita em face aos temas veiculados nos textos e pela sensibilidade diante da organização da linguagem [...]. Em outras palavras, há um posicionamento do leitor frente ao texto. O leitor crítico reflete e transforma as ideias do texto para produzir sua própria interlocução (FRANCISCO JUNIOR, 2011, p. 166).



Fig. 2 - Diagrama do grupo 3. Fonte: Os autores.

Outro ponto a ser destacado é que três grupos construíram o diagrama estabelecendo conexões entre as informações trazidas no TDC, como os modelos dos fones e suas vantagens e desvantagens, e o conteúdo aprendido sobre ondas sonoras. No diagrama do grupo 1 (Fig. 3), por exemplo, os alunos relacionaram o fone de ouvido com a percepção de sons graves e agudos, conhecimento que foi trabalhado em aula e que também estava presente no TDC.

Observa-se, no diagrama do grupo 1, que os alunos, ao descreverem características do fone Headphone, elencaram conteúdos físicos discutidos em aula, tais como os sons graves e agudos e a intensidade do som, e ainda apresentam informações contidas no TDC.

Nessa direção, também se destaca o diagrama do grupo 2, ilustrado na Fig. 4, que apresenta a síntese das ideias sobre os fones Headphone e In-ear e menciona a relação entre "volume" e "tempo de exposição", possivelmente pelo fato de ter sido discutido em aula o tempo máximo de exposição diário de uma pessoa a determinada fonte sonora. Os alunos do grupo 2 deram indícios em seu diagrama de que o uso indevido e excessivo dos fones pode causar danos à audição, o que pode ser observado pelas expressões conectadas às palavras "tímpano" e "volume". 




Fig. 3 - Diagrama do grupo 1. Fonte: Os autores.



Fig. 4 - Diagrama do grupo 2. Fonte: Os autores.

Diante do exposto, constata-se que a AD com o TDC "Para ouvir melhor" viabilizou que os alunos percebessem a importância dos conhecimentos científicos concernentes ao uso e funcionamento dos diferentes modelos de fones de ouvido, bem como conscientizou-os de que o uso inadequado desse dispositivo pode provocar lesões no aparelho auditivo. Assim, foi de extrema importância mostrar para os alunos, os quais não tinham conhecimento do assunto, como a Física está presente no uso e na escolha dos fones de ouvido, ou seja, incorporar/utilizar os conhecimentos científicos para lidar com as questões do cotidiano. 
Vale ressaltar que o TDC utilizado nesta AD continha uma linguagem de fácil compreensão e apresentava imagens que chamavam a atenção dos alunos pelo fato de serem atrativas, motivando, assim, o interesse pela leitura. Desse modo, pode-se perceber que o TDC é um bom recurso para ser utilizado nas aulas que tenham como propósito desenvolver a leitura e a escrita, pois o TDC traduz a linguagem científica para uma linguagem acessível e aborda assuntos que fazem parte do cotidiano dos alunos (TERRAZZAN; GABANA, 2003; MENEGAT; CLEMENT; TERRAZZAN, 2007; ROCHA, 2012b).

\section{Considerações finais}

Por meio da AD implementada, foi possível constatar que o uso do TDC potencializou a contextualização e articulação do conteúdo de ondas sonoras a um artefato presente no cotidiano do aluno: os fones de ouvido. Além disso, percebeu-se que a abordagem proposta motivou os alunos a desenvolverem as atividades de leitura e escrita sugeridas durante todas as etapas.

Os resultados obtidos no decorrer do desenvolvimento da AD apontam um caminho possível para que, nas aulas Física, sejam estimuladas também as habilidades de leitura e escrita. No presente artigo, optou-se por utilizar um TDC, uma vez que a maioria destes textos apresenta uma linguagem acessível e aborda temas presentes no cotidiano dos alunos.

É importante salientar, ainda, que as estratégias utilizadas no transcorrer da AD para as etapas anteriores, concomitantes e posteriores à leitura poderiam ser empregadas para trabalhar qualquer outro tipo de texto (incluindo os do LD). A importância de as práticas de leitura envolverem essas três etapas é explicada pelo fato de que, a partir das atividades propostas em cada uma das etapas, o professor poderá avaliar o que o aluno sabia antes e o que aprendeu depois de ler e discutir o texto em aula. Percebeu-se, também, que os alunos se mostraram motivados, interessados e curiosos durante o desenvolvimento de todas as etapas da AD, o que se deve não só ao assunto abordado no TDC e à sua vinculação com o conteúdo ensinado, mas também à dinâmica proposta em cada etapa de leitura.

Reconhece-se que esta pesquisa desenvolvida em sala de aula apresenta limitações no que se refere aos resultados discutidos, uma vez que estes envolvem um número restrito de alunos em um dado contexto de sala de aula. Entretanto, o que merece destaque é o caráter inovador da atividade de leitura do TDC relatada neste manuscrito, a qual procurou articular a leitura de um TDC ao ensino de conteúdos físicos (no caso ondas sonoras) mediante o uso de estratégias de leitura. Essa nova forma de trabalhar a leitura de TDC nas aulas de Física se diferencia dos trabalhos reportados na literatura, conforme indica o levantamento bibliográfico discutido neste estudo.

Por fim, defende-se que o relato de experiência ora discutido pode servir de inspiração a outros profissionais da educação que, assim como as autoras deste trabalho, percebem a importância da necessária articulação entre leitura e ensino de Física. 


\section{Referências}

ALMEIDA, M. J. P. M. de; SILVA, H. C. da; BABICHAK, C. C. O Movimento, a Mecânica e a Física no Ensino Médio. Revista Brasileira de Ensino de Física. São Paulo, SP, v. 21, n. 1, p. 195-201, Março, 1999.

; MOZENA, E. R. Luz e outras formas de radiação Eletromagnéticas, leitura na $8^{\circ}$ Série do Ensino Fundamental. Revista Brasileira de Ensino de Física. São Paulo, SP, v. 22, n. 3, p. 426-433, Set., 2000.

; SILVA, H. C. da; MACHADO, J. L. M. Condições de produção no funcionamento da leitura na educação em Física. Revista Brasileira de pesquisa em educação em ciências, São Paulo, v. 1, n. 1, Jan. 2001.

ASSIS, A.; TEIXEIRA, O. P. B. Dinâmica discursiva e o ensino de física: análise de um episódio de ensino envolvendo o uso de um texto alternativo. Revistas Ensaio Pesquisa em Educação em Ciências, Minas Gerais, v. 9, n. 2, p. 1-17, Jun. 2007.

et al. Aprendizagem significativa do conceito de ressonância. Revista Brasileira de Pesquisa em Educação em Ciências, São Paulo, v. 12, n. 1, Jan. 2012.

ASSIS, I. C. de; DICKMAN, A. G. A geladeira uma proposta de ensino para a Termodinâmica. In: SIMPÓSIO NACIONAL DE ENSINO DE FÍSICA, 21, 2015, Uberlândia. Atas... São Paulo: SBF, 2015.

BOGDAN, R.; BIKLEN, S. Investigação qualitativa em Educação: Uma introdução à teoria e aos métodos. Portugal: Porto Editora, 1994. 335p.

BOLFE, M. A; CORREIA, D.; SAUERWEIN, I. P. S. Uma proposta de atividade didática com texto de divulgação científica para as aulas de Física do Ensino Médio. In: SIMPÓSIO NACIONAL DE ENSINO DE FÍSICA, 21, 2015, Uberlândia. Atas... São Paulo: SBF, 2015.

BORGES, A. T.; RODRIGUES, B. A. O ensino da Física do som baseado em investigações. Revistas Ensaio Pesquisa em Educação em Ciências, Minas Gerais, v. 7, n. 2, p. 1-24, Dez. 2005.

BRASIL. Ministério da Educação (MEC), Secretaria de Educação Média e Tecnológica. Parâmetros Curriculares Nacionais para o Ensino Médio: Ciências da Natureza, Matemática e suas Tecnologias. Brasília, MEC/Semtec, 1999. Disponível em:

$<$ http://portal.mec.gov.br/seb/arquivos/pdf/ciencian.pdf>. Acesso em: 26 mai. 2015.

DECIAN, E.; CORREIA, D.; SAUERWEIN, I. P. S. Atividade de leitura e escrita nas aulas de Física: A contribuição dos textos de divulgação científica. In: SIMPÓSIO NACIONAL DE ENSINO DE FÍSICA, 21, 2015, Uberlândia. Atas... São Paulo: SBF, 2015. 
DIAS, P. M. C.; SANTOS, W. M. S.; SOUZA, M. T. M. de. A gravitação Universal (Um texto para o ensino médio). Revista Brasileira de Ensino de Física, São Paulo, v. 26, n. 3, p. 257271, Set. 2004.

FERREIRA, L. N. de A.; QUEIROZ, S. L. Textos de Divulgações Científicas no Ensino de Ciências: uma revisão. Alexandria Revista de Educação em Ciência e Tecnologia, Florianópolis, v. 5, n. 1, p. 3-31, Maio 2012.

FRANCISCO JUNIOR, W. E. Analisando uma estratégia de leitura baseada na elaboração de perguntas com respostas. Revista de Investigação em Ensino de Ciências, Porto Alegre, v. 16, n. 1, p. 161-175, 2011.

MARTINS, I.; CASSAB, M.; ROCHA, M. B. Análise do processo de reelaboração discursiva de um texto de divulgação científica para um texto didático. In: ENCONTRO NACIONAL DE PESQUISA EM EDUCAÇÃO EM CIÊNCIAS, 3, 2001, Atibaia. Atas... São Paulo: ABRAPEC, 2001.

MENEGAT, T. M. C.; CLEMENT, L.; TERRAZZAN, E. A. Textos de divulgação científica em aulas de Física: Uma abordagem investigativa. In: ENCONTRO NACIONAL DE PESQUISA EM EDUCAÇÃO EM CIÊNCIAS, 6, 2007, Florianópolis. Atas... São Paulo: ABRAPEC, 2007.

OLIVEIRA, J. M. de L.; ALMEIDA, M. J. P. M. de; FERREIRA, C. U. Leitura de um texto de divulgação científica sobre nanotecnologia no Ensino Médio. In: SIMPÓSIO NACIONAL DE ENSINO DE FÍSICA, 20, 2013, São Paulo. Atas... São Paulo: SBF, 2013.

PASCOALOTO, L. G.; LONDERO, L.; BRUNO JUNIOR, V. Interpretações das Leis da Dinâmica de Newton a partir da leitura de textos por alunos do Ensino Médio. In: SIMPÓSIO NACIONAL DE ENSINO DE FÍSICA, 20, 2013, São Paulo. Atas... São Paulo: SBF, 2013.

RAMOS, J. E. F.; PIASSI, L. P. A leitura do texto literário na aula de Física, possibilidades. In: SIMPÓSIO NACIONAL DE ENSINO DE FÍSICA, 20, 2013, São Paulo. Atas... São Paulo: SBF, 2013.

ROCHA, M. R. Contribuições dos textos de divulgação científicas para o ensino de Ciências na perspectiva dos professores. Revista Acta Scientiae, Canoas, v. 14, n. 1, p. 132-150, Janeiro/Abril 2012a.

O potencial didático dos textos de divulgação científica segundo professores de ciências. Revista Brasileira de Ensino de Ciência e Tecnologia, v. 5, n. 2, p. 47-68, Maio/Agosto 2012b.

RUI, L. R; STEFFANI, M. H. Física: Som e Audição Humana. In: SIMPÓSIO NACIONAL DE ENSINO DE FÍSICA, 17, 2007, São Luiz, MA. Atas... São Paulo: SBF, 2007. 
SALÉM, S.; KAWAMURA, M. R. O texto de divulgação e o texto didático: conhecimentos diferentes? In: ENCONTRO DE PESQUISA EM ENSINO DE FÍSICA, 5, 1996, Belo Horizonte. Atas... São Paulo: SBF, 1996.

SETLIK, J.; HIGA, I. Leitura e produção escrita no Ensino Médio como meio de produção de conhecimento. Revista Experiências em Ensino de Ciências, Cuiabá, v. 9, n. 1, p. 83-95, Dez. 2014.

. A leitura e a escrita em uma aula sobre a conservação da Energia Mecânica. In: SIMPÓSIO NACIONAL DE ENSINO DE FÍSICA, 21, 2015, Uberlândia. Atas... São Paulo: SBF, 2015.

SILVA, A. C. da; ALMEIDA, M. J. P. M de. A leitura por alunos do Ensino Médio de um texto considerado de alto grau de dificuldade. Alexandria: Revista de Educação em Ciência e Tecnologia, Florianópolis, v. 7, n. 1, p. 49-73, Maio 2014.

A noção de mobilização na associação da Física a objetos tecnológicos contemporâneos. Revista Ciência e Educação, Bauru, SP, v. 21, n. 2, p. 417-434, 2015.

SILVA, E. T. da. Ciência, leitura e escola. In: Almeida, Maria José P. M. de; Silva, Henrique César da. (Orgs.). Linguagens, Leituras e ensino de ciências. Campinas: Mercado das Letras ALB, 1998. Cap. 7, p. 121-130, 206p.

SILVA, I. M. N. et al. O uso de textos de divulgação científica no Ensino de Física com duas estratégias. In: SIMPÓSIO NACIONAL DE ENSINO DE FÍSICA, 21, 2015, Uberlândia. Atas... São Paulo: SBF, 2015.

SILVA, J. A. da; KAWAMURA, M. R. D. A natureza da luz: uma atividade com texto de divulgação científica em sala de aula. Caderno Brasileiro de Ensino de Física, Florianópolis, v.18, n. 3, p.316-339, Ago. 2001.

SILVA, W. M.; ZANOTELLO, M. O debate científico escolar como estratégia para a leitura de textos de divulgação científica. In: SIMPÓSIO NACIONAL DE ENSINO DE FÍSICA, 21, 2015, Uberlândia. Atas... São Paulo: SBF, 2015.

SOLÉ, I. Estratégia de Leitura. Porto Alegre: Artmed, 1998. 194p.

STEFFANI, M. H.; DAMASIO, F. Leitura, escrita e expressão oral em Física. In: PEREIRA, Nilton Mullet et al. (Orgs). Ler e Escrever: compromisso no Ensino Médio. Porto Alegre: Editora da UFRGS, 2008. 313p.

TERRAZZAN, E. A.; GABANA, M. Um estudo sobre o uso de atividades didáticas com texto de divulgação científica em aulas de física. In: ENCONTRO NACIONAL DE PESQUISA EM EDUCAÇÃO EM CIÊNCIAS, 4, 2003, Bauru. Atas... São Paulo: ABRAPEC, 2003. 
ZANOTELLO, M.; ALMEIDA, M. J. P. M. de. Leitura de um texto de divulgação científica em uma disciplina de física básica na educação superior. Revista Ensaio, Belo Horizonte, v. 15, n. 3, p. 113-130, Set/Dez, 2013. 